\title{
Estratégias e Metodologias para o Ensino-Aprendizagem da Operação Aritmética da Multiplicação utilizando Tópicos da História da Matemática
}

\author{
Helena de Fátima Sousa Melo \\ Maria do Carmo Carvalho Sousa da Cunha Martins
}

\section{Resumo}

As dificuldades no ensino-aprendizagem das operações aritméticas podem interferir na aquisição de algumas competências matemáticas básicas e, de certo modo, influenciar futuros processos de cálculo. Uma abordagem diferente, como a utilização de tópicos de História da Matemática, pode revelar-se uma boa estratégia para motivar os alunos e encaminhá-los para um conhecimento eficaz das referidas operações. Muitos foram os povos que aplicaram técnicas, processos, métodos e algoritmos na resolução de problemas do quotidiano ao longo da história. A Matemática de então tinha um cunho mais prático do que teórico, que decorria diretamente das necessidades diárias. Abordando estes meios ancestrais podemos cativar e estimular os alunos para as operações aritméticas, nomeadamente, a operação de multiplicação. Neste trabalho descrevemos o modo como alguns povos procediam à operação de multiplicação, bem como os métodos usados para tal, nomeadamente: a duplicação no Antigo Egito; a gelosia e o zigzag na India medieval; os bastões de Napier; a multiplicação com as mãos no Renascimento; e o processo de multiplicação do povo Yoruba.A utilização de diversos ábacos e o uso de outros materiais de efeito similar, como os bastões de Napier, podem ser um excelente complemento às estratégias para a aprendizagem da operação de multiplicação.

Palavras-chave: operação de multiplicação; história da matemática

\begin{abstract}
The difficulties in teaching-learning of arithmetic operations can interfere with the acquisition of some basic mathematical skills and, in a way, influence future computation processes. A different approach, such as the use of topics in the History of Mathematics, may prove to be a good strategy to motivate students and direct them to an effective knowledge of such operations. Many people have applied techniques, processes, methods, and algorithms to solve everyday problems throughout history. The Mathematics of that time had a more practical rather than a theoretical character, which came directly from the daily necessities. Approaching these ancestral techniques, we can call attention for and stimulate students for arithmetic operations, namely, the multiplication operation. In this presentation we present the way in which some people performed the multiplication operation, as well as the methods used for such: duplication in Ancient Egypt; "gelosia" and zigzag in medieval India; Napier's bones; multiplication with hands in the Renaissance; and the multiplication process of the Yoruba people. The use of several abacuses and of other materials of similar effect, such as the Napier rods, can be an excellent complement to the strategies for learning the multiplication operation.
\end{abstract}

Keywords: multiplication operation; History of Mathematics

\section{INTRODUÇÃO}

A operação de multiplicação, como sabemos, é a abreviação de uma operação de adição quando todas as suas parcelas são iguais. Por exemplo, na operação de adição $4+4+4+4+4$, a parcela 4 aparece cinco vezes, pelo que podemos reescrever esta expressão numérica como $5 \times 4$, sendo 5 o multiplicador (as vezes em que a parcela aparece) e 40 multiplicando (o valor da parcela que se repete). Por este motivo, algumas vezes também será referenciada a operação de adição. 
No decorrer do trabalho para além das referências históricas dos diversos métodos de multiplicação ao longo do tempo, também serão apresentadas algumas estratégias de ensino laprendizagem e possíveis metodologias utilizando esses métodos.

O processo de ensino/aprendizagem, segundo Kubo e Botomé (2005), é um sistema de interação entre professor e aluno, onde a sua interdependência é fundamental para a compreensão do que ocorre, bem como o seu entendimento e percepção estabelecem o essencial para o desenvolvimento dos trabalhos de aprendizagem ou de ensino".

Entenda-se, no texto, por estratégias de ensino/aprendizagem:

um conjunto de acções do professor ou do aluno orientadas para favorecer 0 desenvolvimento de determinada competência de aprendizagem que se tem em vista.0 termo estratégia implica um plano de aç̧ão para conduzir o ensino em direção a propósitos fixados, servindo-se de meios (A. Ribeiro e L. Ribeiro): "Como atingir um dado propósito?". ${ }^{2}$

Por vezes, há uma confusão entre os termos "estratégia" e "metodologia", pois alguns autores utilizam-nas como sinónimos. Assim, referimos que o termo metodologia será entendido como na perspetiva de Nérici (1987) em que:

a metodologia do ensino inclui método e técnicas de ensino, cuja diferenciação não é muito clara. Pode-se dizer que o método efetiva-se por meio de técnicas de ensino que são utilizadas para alcançar os objetivos por ele instituídos. Desta forma, Nérici (1987, p.285) define método de ensino como um "conjunto de procedimentos lógica e psicologicamente ordenados" utilizados pelo professor a fim de "levar o educando a elaborar conhecimentos, adquirir técnicas ou habilidades e a incorporar atitudes e ideais". Já as técnicas de ensino são "destinadas a dirigir a aprendizagem do educando, porém, num setor limitado, particular, no estudo de um assunto, ou num setor particular de um método de ensino", portanto, o método de ensino é mais amplo que a técnica ${ }^{3}$

\section{A OPERAÇÃO DE MULTIPLICAÇÃO NO ANTIGO EGITO E A SUA APLICAÇÃO NOS DIAS DE HOJE}

\footnotetext{
${ }^{1}$ O. M. Kubo \& S. P.; Botomé, "Ensino-aprendizagem: uma interação entre dois processos comportamentais", Interação em Psicologia, 5, (2005):1

https://revistas.ufpr.br/psicologia/article/view/3321.

${ }^{2}$ R. M. Vieira \& C. Vieira, Estratégias de ensino/aprendizagem, (Lisboa: Instituto Piaget, 2005), 16

3 J. Brighenti, V. T. Biavatti \& T. R. Souza, "Metodogias de ensino/aprendizagem: uma abordagem sob a percepção dos alunos", Revista GUAL 8, n. 3, (Florianópolis, set. 2015): 281-304, 290
} 
O povo do antigo Egito possuía um sistema de numeração decimal, não posicional, utilizando símbolos pictóricos, os hieróglifos, para a representação das quantidades. Usavam sete símbolos: bastão, osso de calcanhar invertido, corda enrolada, flor de lótus, dedo, girino ou peixe, e homem sentado, para as potências de $10^{4}$, desde o expoente 0 até ao expoente 6 , respetivamente (figura 1). Por ser um sistema de numeração aditivo, obtinham as representações dos números através da repetição dos símbolos até perfazerem nove, substituindo pelo símbolo imediatamente superior quando atingiam dez. Nessa ordem de ideias, a maior quantidade que poderiam representar era 9.999.999. Para expressarem, por exemplo, a quantidade 2.345, utilizavam a representação de duas flores de lótus, três cordas enroladas, quatro ossos de calcanhar invertido e cinco bastões. Como o sistema era aditivo, não havia a necessidade de um símbolo para a representação do zero. Assim, se queriam expressar 203, utilizavam apenas duas cordas enroladas e três bastões verticais.

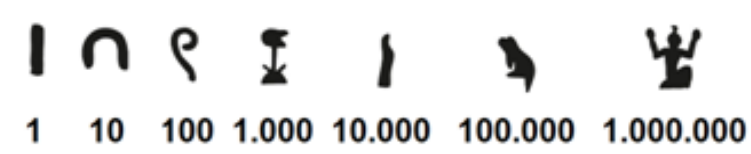

Figura 1: Numeração egípcia

A operação aritmética fundamental, no antigo Egito, era a adição. As outras operações eram efetuadas por sucessivas adições, ou seja, por duplicações, não apresentando-se qualquer dificuldade. Assim, o povo egípcio fazia apenas a junção dos símbolos nesta operação e a respetiva substituição por símbolos superiores quando era necessário.

A operação de multiplicação era feita através do Método de Duplicação, ou Regra do Dobro. Podemos observar na figura 2, o referido processo que mostra o cálculo do produto de 12 por 12.

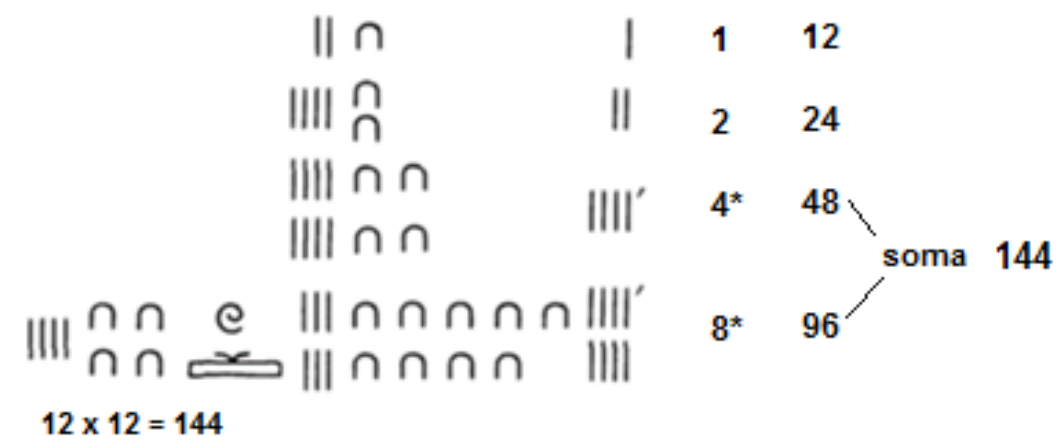

Figura 2: Método de Duplicação para a operação de multiplicação

\footnotetext{
${ }^{4}$ Carl B. Boyer, História da Matemática, trad. Elza F. Gomide (São Paulo: Editora Edgard Blücher, 1976), 8
} 
Este Método de Duplicação consiste em construir duas colunas, uma iniciada com um dos fatores e a outra iniciada com a unidade, em que vamos duplicando-as e parando-se quando obtemos, na coluna iniciada pela unidade, um valor superior ao segundo fator da multiplicação. Nessa mesma coluna, assinalamos quais os valores que adicionados possuem a soma igual ao segundo fator da multiplicação e de seguida adicionamos os correspondentes valores na coluna que foi iniciada com o primeiro fator. A adição desses últimos valores é o produto dessa multiplicação. ${ }^{5}$ Utilizando 0 exemplo da figura 2, temos uma coluna com apenas 1, 2, 4 e 8, visto que 16 é maior do que 12, e na outra coluna temos 12, 24, 48 e 96 , respetivamente. Visto que 12 é igual à soma entre 4 e 8 , fazemos $48+96$, que são os valores associados, obtendo-se o correspondente produto de $12 \times 12$, ou seja, 144 .

Como estratégia para o primeiro contacto com a operação de multiplicação, considerando-a como a adição de parcelas iguais, podemos utilizar a maneira como o povo egípcio fazia a operação de adição, em que se contam os símbolos envolvidos numa mesma ordem de numeração e ao obtermos dez símbolos iguais, substituímos pelo símbolo de valor imediatamente superior. Assim, podemos justificar, na adição, o surgimento de algarismos em ordens superiores num numeral. Por exemplo, quando adicionamos 26 e 78, temos que $6+8$ é igual a uma dezena e quatro unidades. Surge assim o algarismo 1 na ordem das dezenas, cujo valor deverá ser adicionado a 2 e a 7, os valores dos algarismos dessa mesma ordem. Com isso reforçamos a ideia que cada algarismo, num numeral, ocupa um lugar denominado de "ordem", sendo estas a ordem das unidades, das dezenas e das centenas; a cada três ordens, temos uma classe, sendo estas a classe das unidades, dos milhares, dos milhões, dos milhares de milhão, etc.; a cada duas classes temos um grupo, iniciando-se com o grupo das unidades, depois 0 dos milhões, seguindo o dos biliões, e assim por diante.

Utilizando a Metodologia Montessoriana e numa passagem do concreto para o abstrato, podemos utilizar o "Material Dourado", criado pela médica italiana Maria Montessori (1870 - 1952), associando, respetivamente, ao cubo pequeno (unidade) o bastão, à barra (dezena) o osso de calcanhar invertido, à corda enrolada (centena) a placa e ao cubo maior (unidade de milhar) a flor de lótus. (figura 3)

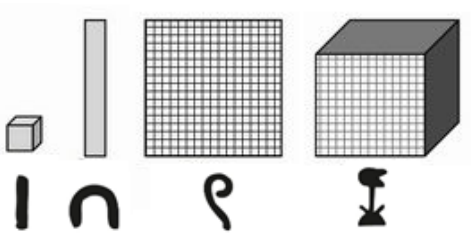

Figura 3: Correspondência entre o "Material Dourado" e os numerais egípcios

\footnotetext{
${ }^{5}$ Ibid., 11
} 
Esta abordagem permite realçar e consolidar o facto de cada ordem superior corresponder a dez quantidades na ordem inferior e vice-versa.

Estes procedimentos podem ser utilizados como motivação para as tabuadas de multiplicação, iniciando-se com a tabuada do 2, em virtude da regra do dobro, e promover o estudo das regularidades.

A figura 4 ilustra a aplicação do Método da Duplicação do povo egípcio para a construção da tabuada de multiplicação do 2. Podendo ser aplicado às tabuadas de multiplicação do 4, por ser o dobro de 2, e do 8, por ser o dobro de 4.

\begin{tabular}{c|c|c} 
Tabuada do 2 & $\begin{array}{c}\text { Construção do multiplicando } \\
\text { Soma de potência de } 2\end{array}$ & $\begin{array}{c}\text { Construção do produto } \\
\text { Duplicação das parcelas } \\
(2=1+1)\end{array}$ \\
$2 \times 1=2$ & $(2=1+1)$ & $(4=2+2)$ \\
$2 \times 2=4$ & $(3=1+2)$ & $(6=2+4)$ \\
$2 \times 4=8$ & $(4=2+2)$ & $(8=4+4)$ \\
$2 \times 5=10$ & $(5=1+4)$ & $(10=2+8)$ \\
$2 \times 6=12$ & $(6=2+4)$ & $(12=2+8)$ \\
$2 \times 7=14$ & $(7=1+2+4)$ & $(14=2+4+8)$ \\
$2 \times 8=16$ & $(8=4+4)$ & $(16=8+8)$ \\
$2 \times 9=18$ & $(9=1+8)$ & $(18=2+16)$ \\
$2 \times 10=20$ & $(10=2+8)$ & $(20=4+16)$
\end{tabular}

Figura 4: Construção da tabuada de multiplicação do 2

Para anos mais avançados, do $2 .{ }^{\circ}$ ciclo e $3 .{ }^{\circ}$ ciclo do Ensino Básico, o Método da Duplicação proporciona um desenvolvimento no cálculo mental, como estratégia alternativa e fornece uma outra alternativa para a confirmação de resultados obtidos na multiplicação sem recorrer-se ao uso da calculadora.

\section{A OPERAÇÃo DE MULTIPLICAÇÃo dA INDIA MEDIEVAL NO ENSINO BÁSICO ATUAL}

Acredita-se que os nossos algoritmos das operações aritméticas tenham tido início na Índia. Segundo Boyer:

A adição e a multiplicação eram efetuadas na Índia de modo muito semelhante ao que usamos hoje, só que parecem a princípio ter preferido escrever os números como as unidades menores à esquerda, portanto trabalhar da esquerda para direita, usando pequenas lousas com tinta removível branca ou uma tábua coberta de areia ou farinha. ${ }^{6}$

\footnotetext{
6 Ibid., 158.
} 
Também é referenciado por Eves:

A adição hindu antiga talvez fosse efetuada da esquerda para a direita, e não ao contrário como preferimos hoje. ${ }^{7}$

Na época do matemático e astrónomo hindu Aryabhata I (c. 476 - c. 550) presumimos que eram bem conhecidas as quatro operações aritméticas elementares entre os números positivos, quer inteiros, quer fracionários. De acordo com o matemático hindu Bhaskara I (c. 600 - c. 680), as operações aritméticas eram derivadas das operações de adição e de subtração. Na mesma época, o matemático e astrónomo Brahmagupta (c. 598 - c. 670) apresentou, na sua obra, datada de 628, Brahmasputha Siddhanta (a abertura do universo), alguns métodos para a realização da operação de multiplicação entre números inteiros, sendo o primeiro desses conhecido pelo nome Método do Zigzag ${ }^{8}$. Esse Método é muito semelhante ao algoritmo utilizado atualmente. Exemplifiquemos fazendo o cálculo de 1.234 multiplicado por 567. O processo inicia-se com a colocação em duas colunas do multiplicador e do multiplicando. Sendo a coluna da esquerda, escrita na vertical, para o multiplicador, 567, e a da direita, escrita na horizontal, para o multiplicando, 1.234, que é escrito tantas vezes quanto a quantidade de algarismos do multiplicador. A coluna da direita é preenchida com os produtos parciais das sucessivas multiplicações. Em primeiro lugar multiplicamos o número 1.234 por 5 , que ocupa a ordem das centenas em 567 , depois multiplicamos por 6, que ocupa a ordem das dezenas e por último, por 7, que ocupa a ordem das unidades, sempre efetuando o cálculo da direita para a esquerda e alinhando em relação à ordem do multiplicando, como mostra a figura 5.

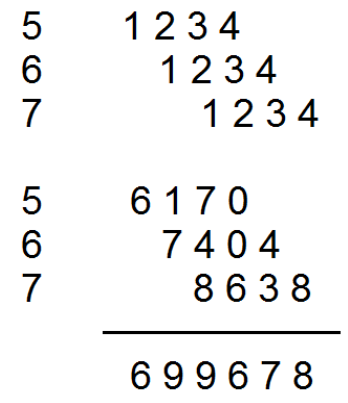

Figura 5: Método do Zigzag

\footnotetext{
${ }^{7}$ Howard Eves, Introdução a História da Matemática, trad. Hygino H. Domingues (São Paulo: Editora da Unicamp, 2005),. 253

8 M. F. Estrada, C. C. Sá, J. F. Queiró, M. C. Silva \& M. J. Costa, História da Matemática, (Lisboa: Universidade Aberta, 2000), 379
} 
Outro método que parece ter a sua origem na Índia, desde o século XII, é o algoritmo conhecido como "Método da Gelosia", ou "multiplicação em grade". Esse método foi posteriormente levado pelos árabes para a China, a Pérsia e a Arábia, seguindo para a Europa Ocidental. ${ }^{9}$

Para a descrição do Método da Gelosia, utilizemos os dados do exemplo anterior. Assim, sendo um dos fatores composto por quatro algarismos e o outro composto por três algarismos, construímos um quadriculado 4 por 3 , com as 12 quadrículas divididas pelas respetivas diagonais, todas na mesma direção, ou seja, da esquerda para a direita no sentido ascendente, e escrevemos os dois fatores da multiplicação, um na parte superior do quadriculado, da esquerda para a direita (na horizontal) e o outro à direita do quadriculado, de cima para baixo (na vertical), alinhados com cada quadrícula (passo 1 da figura 6). As quadrículas, que estão indicadas por quadrados e divididas pelas respetivas diagonais, serão completadas com os produtos parciais correspondentes aos algarismos da sua coluna e da sua linha. $A$ diagonal divide a quadrícula em dois espaços, na parte superior é colocada a dezena e na parte inferior a unidade de cada produto parcial (passo 2 da figura 6). Por último, no sentido da direita para a esquerda, adicionamos os algarismos de cada fila de diagonais, escrevendo a unidade dessa soma no extremo inferior e adicionando, na diagonal seguinte, a dezena resultante da adição anterior (passo 3 da figura 6).

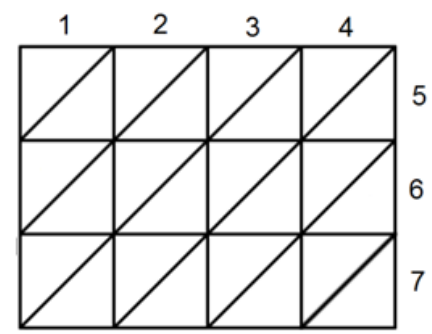

passo 1

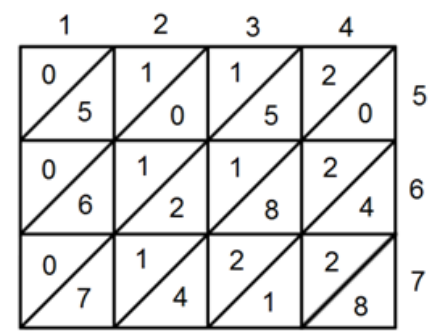

passo 2

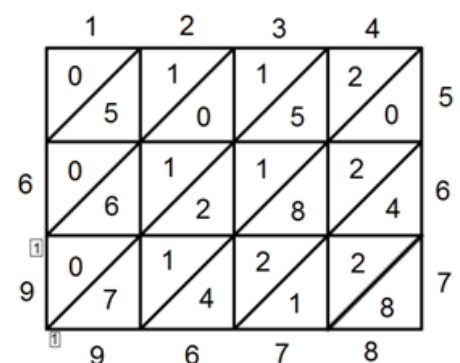

passo 3

Figura 6: Método da Gelosia

Os algoritmos apresentados para a multiplicação, promovem uma estratégia para o processo de ensino-aprendizagem dessa operação aritmética. O Método da Gelosia, para além de facilitar os cálculos dos produtos parciais, proporciona a possibilidade de construir e implementar jogos que motivem o seu exercício.

Apresentamos, como exemplo motivador de uma das utilizações do Método da Gelosia no ensino-aprendizagem da operação de multiplicação, o jogo "Brincar x Gelosia" (figura 7), desenvolvido em 2013/14 pelas alunas: Carla Machado, Melissa Garcia, Raquel Medeiros e Sara Paulino, inscritas na unidade curricular de História do Pensamento Matemático da Licenciatura em Educação Básica da

\footnotetext{
${ }^{9}$ Carl B. Boyer, História da Matemática, trad. Elza F. Gomide (São Paulo: Editora Edgard Blücher, 1976), 158
} 
Universidade dos Açores e aplicado ao 1. ${ }^{\circ}$ Ciclo do Ensino Básico numa das atividades desenvolvidas no "Dia da Criança", no atelier Matemagicolândia em Ponta Delgada na ilha São Miguel.

O jogo, disputado por duas equipas, é constituído por um tabuleiro quadrado com $100 \mathrm{~cm}$ de lado, onde, em cada face, está desenhada uma gelosia 2 por 2, uma para cada equipa. Utilizam-se 120 cartões, cada um numerado com um algarismo de 0 a 9 , e uma ampulheta que serve para controlar 0 tempo máximo do jogo. Em cada espaço assinalado no tabuleiro, 16 no total, encontra-se uma bolsa transparente para receber os cartões numerados. Um jogador de cada equipa retira sucessivamente quatro cartões, que devem ser colocados nas bolsas do tabuleiro ao redor da gelosia no sentido horário. Os jogadores das equipas apresentam os produtos parciais, colocando nas bolsas os respetivos algarismos, e por fim executam a adição. Vence o jogo a primeira equipa a finalizar por completo o placar.

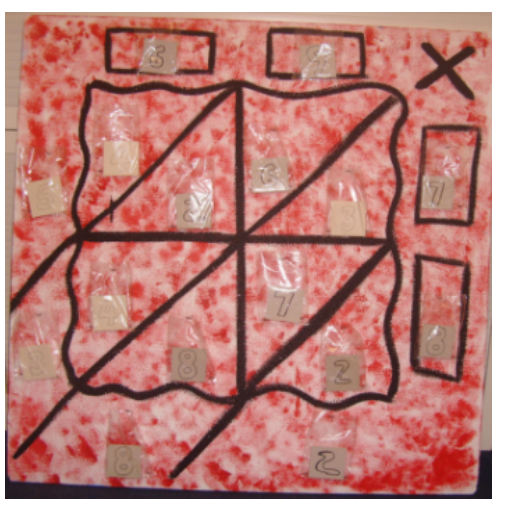

Figura 7: Uma face do plcr do ogo com a gelosia

Utilizando como estratégia o Método do Zigzag, podemos enfatizar o conceito da ordem, classe e grupo dos numerais envolvidos, quer no multiplicador, quer no multiplicando. Para além disso, permite ainda, através de sua história, uma primeira abordagem para a execução do algoritmo da multiplicação na vertical. (figura 8)

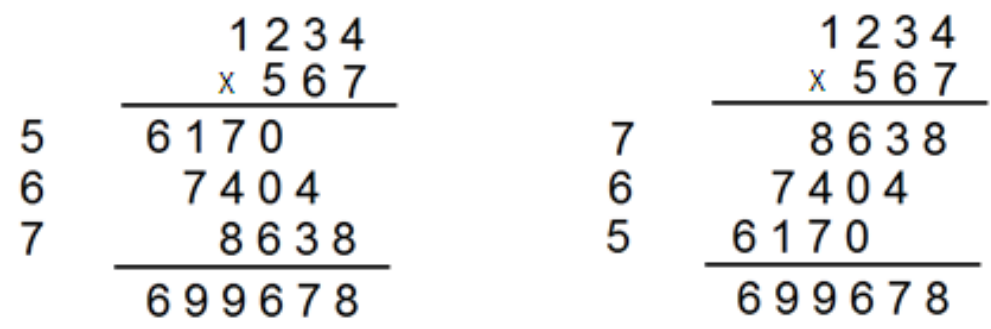

Figura 8: Método do Zigzag e a propriedade comutativa da multiplicação 


\section{A MULTIPLICAÇÃO COM OS BASTÕES DE NAPIER E A SUA APLICAÇÃO NO $1 .^{\circ}$ CICLO DO ENSINO BÁsICO}

Segundo Eves:

Eram tão amplas as dificuldades experimentadas na multiplicação de números grandes que se buscaram métodos mecânicos para levar a cabo o processo. Nesse sentido a invenção de Napier, conhecida como barras de Napier ou ossos de Napier, descrita em seu trabalho, Rabdologiae, publicado em 1617, conseguiu alcançar muita fama. [... $]^{10}$

Em princípio o Método dos Bastões ou Barras de Napier não difere muito do Método da Gelosia, mas a sua prática utiliza tiras, quer de osso, de metal, de madeira ou de papel, onde cada uma contém os múltiplos de cada um dos algarismos de 0 a 9, como podemos ver na figura 9a. Para a sua manipulação, colocamos lado a lado as tiras encabeçadas pelos algarismos que compõem o numeral do multiplicando, e depois adicionamos os valores correspondentes aos algarismos que compõem o numeral do multiplicador, obtendo os produtos parciais que adicionados resultam no produto final.

Como exemplo, façamos a multiplicação de 527.436 por 7 . Assim, colocamos as tiras encabeçadas pelos algarismos 5, 2, 7, 4, 3 e 6, lado a lado, como mostra a figura $9 \mathrm{~b}$, e podemos obter 0 produto desejado, facilmente, apenas com a adição de no máximo dois algarismos, na linha relativa aos múltiplos de 7 (figura 9c).

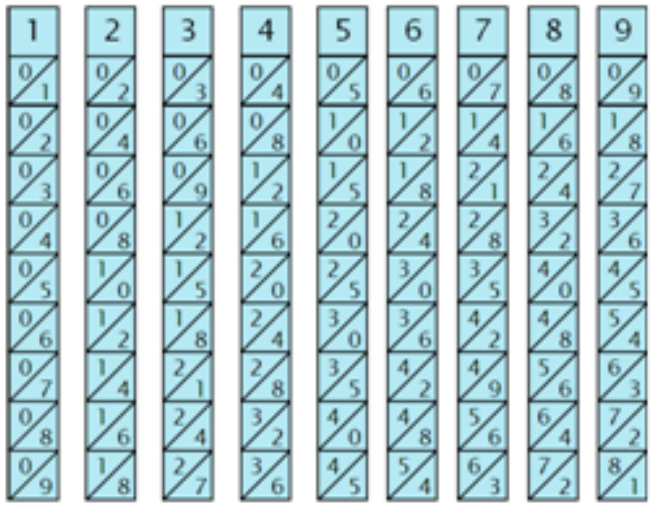

a)

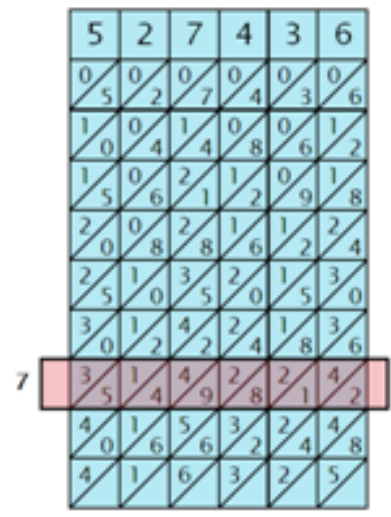

b)

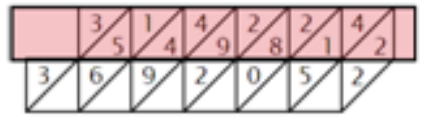

c)

Figura 9: a) Bastões de Napier, b) Produto 527.436 x 7, c) Produto 3.692 .052

Para a multiplicação entre números com mais de um algarismo, procedemos do mesmo modo, fazendo a adição dos produtos parciais de acordo com a ordem dos algarismos do multiplicador, ou seja,

\footnotetext{
${ }^{10}$ Howard Eves, Introdução a História da Matemática, trad. Hygino H. Domingues (São Paulo: Editora da Unicamp, 2005), 369
} 
para a ordem das dezenas, multiplicamos o produto parcial por 10, para a ordem das centenas, multiplicamos o produto parcial por 100 e assim por diante.

A sua aplicação, como estratégia no ensino-aprendizagem das operações de multiplicação e divisão, é inerente, visto ser um processo de simples manipulação cujas componentes são facilmente construídas quer em madeira ou cartão. Pela sua própria estrutura, não requer propriamente a memorização da tabuada da multiplicação, uma vez que cada barra possui a tabuada referente aos nove primeiros números. Contudo a aplicação desta estratégia ajuda a fixar a tabuada.

Este processo foi aplicado em algumas turmas do $2 .^{\circ}$ e $3 .^{\circ}$ anos do $1 .^{\circ}$ Ciclo do Ensino Básico como uma das atividades do atelier Matemagicolândia no "Dia da Criança" em Ponta Delgada na ilha São Miguel, bem como em turmas de alunos com necessidades educativas especiais numa escola de Ponta Delgada.

Observamos que, na operação de multiplicação são colocadas lado a lado as tiras correspondentes quer ao multiplicando, quer ao multiplicador, e efetuar a operação, como já foi referido anteriormente.

\section{A OPERAÇÃO DE MULTIPLICAÇÃO NO RENASCIMENTO E SUA UTILIZAÇÃO NOS CICLOS DO ENSINO BÁSICO}

Em virtude de serem poucas as pessoas que, durante a Idade Média e o Renascimento, conheciam a tabuada de multiplicação para além da do 5 , passaram a utilizar uma variedade de métodos simples para calcular o produto dos números superiores a 5 . Descrevemos a parte do método que se baseia nos Complementares Aritméticos quando os valores estão entre 6 e 10.

Por exemplo, se queremos calcular $6 \times 8$, usamos os seus complementos aritméticos, 4 e 2, respetivamente, e depois consideramos os complementares destes em relação a 5 , ou seja, 1 e 3 , respetivamente. Ao efetuar a adição desses últimos números obtemos o algarismo das dezenas, 4, e ao fazer o produto dos complementos aritméticos, obtemos o algarismo das unidades, 8 . Assim, $6 \times 8=48$.

Para tal, era costume utilizar os dedos das mãos como instrumento de cálculo, em que a cada dedo era associado um número, iniciando com o mindinho (6) e terminando no polegar (10). O produto era resultante da junção dos dedos (em cada mão) correspondentes aos números que queriam multiplicar, através do seguinte procedimento (figura 10a):

1..$^{\circ}$ Multiplicavam os dedos superiores que eram os complementos de cada fator da multiplicação (em relação a 5);

2. ${ }^{\circ}$ Adicionavam os dedos de contacto e os dedos abaixo que foram multiplicados por 10;

3..$^{\circ}$ Adicionavam o produto do $1 .^{\circ}$ passo com a soma do $2 .^{\circ}$, obtendo assim o produto final. 
Este procedimento pode ser utilizado como estratégia para o cálculo da tabuada de multiplicação do 6 ao 10 nos $1 .^{\circ}$ e $2 .{ }^{\circ}$ Ciclos do Ensino Básico. Esta estratégia pode ser transformada numa metodologia para o ensino/aprendizagem das respetivas tabuadas, visto que já há testemunhos na ilha de São Miguel da sua aplicação a alunos do $3 .^{\circ}$ ano com dificuldades de memorização que obtiveram sucesso na dedução da tabuada de multiplicação do 6 , a qual consta no conteúdo de Números e Operações do $2 .{ }^{\circ}$ ano do Programa e Metas Curriculares de Matemática para o Ensino Básico, homologado em 2013.

Este recurso à multiplicação com as mãos pode também ser usado para as meias dezenas superiores a 10, recomendado ao $3 .^{\circ}$ Ciclo do Ensino Básico e Ensino Secundário. Para tal há a necessidade do conhecimento de uma tabela de valores (tabela 1) onde distingue-se os processos entre as meias dezenas cujo último algarismo é o 0 e as meias dezenas cujo último algarismo é 5 . Esta estratégia pode auxiliar o cálculo mental para os anos mais avançados do Ensino Básico e mesmo no Ensino Secundário. Este processo foi muito utilizado no Renascimento e, pelo que tudo indica, ainda hoje é utilizado nas zonas rurais da Europa e da Rússia. ${ }^{11}$

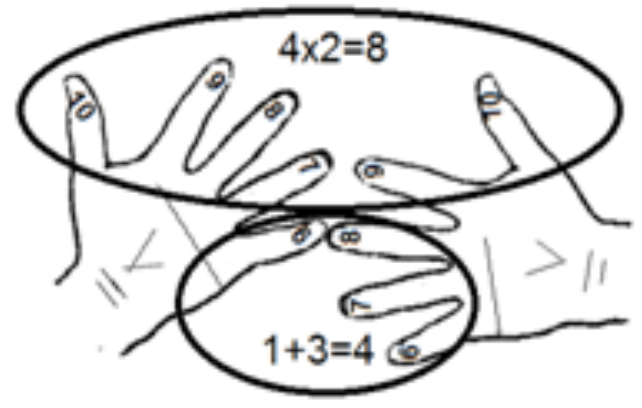

a)

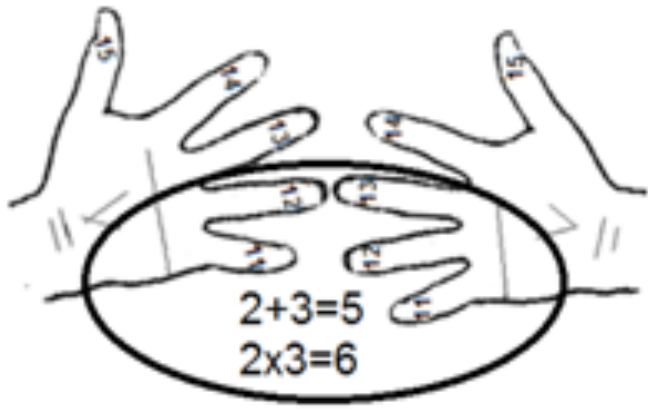

b)

Figura 20: a) $6 \times 8$, b) $12 \times 13$

Assim, quando o último algarismo das meias dezenas for 0, ou seja, de 6 a 10, de 16 a 20, etc., o processo é o descrito anteriormente recorrendo à informação da tabela 1. Quando o último algarismo das meias dezenas for 5 , isto é, de 11 a 15 , de 21 a 25 , etc., o processo sofre uma ligeira modificação, pois deixamos de usar o número de dedos acima dos dedos de contacto.

Por exemplo, no cálculo $12 \times 13$, temos, incluindo os dedos de contacto, 2 e 3 dedos respetivamente (figura 10b), com os quais efetuamos primeiramente a adição obtendo o algarismo das dezenas, 5 , e depois a multiplicação obtendo 0 algarismo das unidades, 6 . Ao numeral 56 acrescentamos uma centena. Assim, $12 \times 13=156$.

${ }^{11}$ M. Gardner, O Festival Mágico da Matemática, (lisboa: Gradiva, 1994), 95 
Tabela 1: Valores a considerar para a multiplicação com as mãos

\begin{tabular}{c|c|c}
\hline Meias dezenas & $\begin{array}{c}\text { Valor dos dedos de contacto e } \\
\text { abaixo }\end{array}$ & Constante aditiva \\
\hline $11-15$ & 10 & 100 \\
\hline $16-20$ & 20 & 200 \\
\hline $21-25$ & 20 & 400 \\
\hline $26-30$ & 30 & 600 \\
\hline $31-35$ & 30 & 900 \\
\hline $36-40$ & 40 & 1200 \\
\hline $41-45$ & 40 & 1600 \\
\hline $46-50$ & 50 & 2000 \\
\hline
\end{tabular}

\section{A OPERAÇÃO DE MULTIPLICAÇÃO DO POVO YORUBA E A SUA APLICAÇÃO RECORRENDO AO ÁBACO VERTICAL}

O povo Yoruba, natural do sudoeste da Nigéria, utiliza um sistema de numeração vigesimal, recorrendo a uma contagem ora aditiva, ora subtrativa. Os múltiplos de 20 e os múltiplos de 200 são usados para expressar as quantidades. Por exemplo, $14=10+4 ; 18=20-2 ; 35=(20 \times 2)-5 ; 40=(20 \times$ 2); $50=(20 \times 3)-10 ; 107=(20 \times 6)-10-3 ; 215=400-(20 \times 4)-5 ; 525=(200 \times 3)-(20 \times 4)+5$, e assim por diante.

Os Yorubas, para executarem a operação de multiplicação, dispõem de 20 pilhas com 20 conchas cada, de onde retiram quer as conchas, quer as pilhas, de acordo com os valores apresentados nos fatores da multiplicação ${ }^{12}$. Por exemplo, o cálculo do produto de 16 por 18 é feito retirando 2 conchas de cada uma das 20 pilhas, ficando 18 conchas em cada uma das pilhas, pois $18=20-2$, e de seguida, são retiradas 4 pilhas, ficando apenas 16 pilhas com 18 conchas cada, pois $16=20-4$. (figura 11)

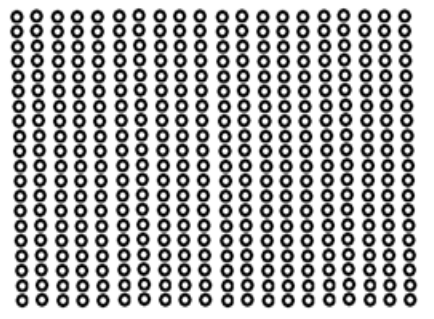

$20 \times 20$

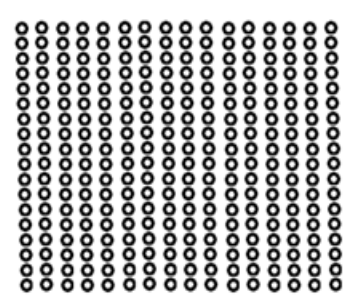

$16 \times 18$

Figura 31: Multiplicação do povo Yoruba

\footnotetext{
12 M. F. Estrada, C. C. Sá, J. F. Queiró, M. C. Silva \& M. J. Costa, História da Matemática, (Lisboa: Universidade Aberta, 2000), 199
} 
Podemos ter dois procedimentos.

Primeiro: As 4 pilhas retiradas com 18 conchas cada, são reorganizadas em 3 pilhas com 20 conchas cada e mais uma pilha com 12 conchas onde ficam a faltar 8 conchas para completa-la. Assim, 0 produto obtido irá refletir todo este processo, ou seja, $4 \times 18=3 \times 20+(20-8)$. E assim, como $16 \times 18$ é igual a $(20-4) \times(20-2)$, temos $16 \times 18=400-(2 \times 20)-(3 \times 20)-(20-8)=288$.

Segundo: Podemos reorganizar as conchas que não foram retiradas obtendo 14 pilhas de 20 conchas cada e faltam 12 conchas para uma nova pilha, ou seja, há uma pilha com apenas 8 conchas. $E$ verificamos que $16 \times 18=(20 \times 14)+8=288$.

Dos dois procedimentos acima descritos, o primeiro é o mais usual pelo povo Yoruba.

Podemos utilizar este raciocínio do Método de Multiplicação Yoruba como estratégia para 0 ensino-aprendizagem da operação de multiplicação. Como o nosso sistema de numeração é decimal, fazemos uma adaptação, utilizando, para os primeiros produtos, 10 bastões, com 10 fichas esféricas em cada um. (figura 12a)

llustremos a adaptação para o cálculo de $6 \times 7$ calculando o produto resultante de 7 multiplicado por 6, em que 7 é o multiplicando e 6 é o multiplicador. Como 7 corresponde à diferença entre 10 e 3 , e 6 corresponde à diferença entre 10 e 4, retiramos de cada um dos bastões 3 fichas esféricas, ficando cada bastão com 7 fichas, e de seguida retiramos 4 dos 10 bastões, ficando assim 6 bastões com 7 fichas cada (figura 12b). Reorganizando as fichas, no sentido de cada bastão ter 10 fichas, obtemos 4 bastões completos e 2 fichas num outro bastão (figura 12c).

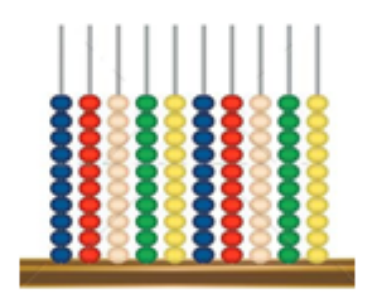

a)

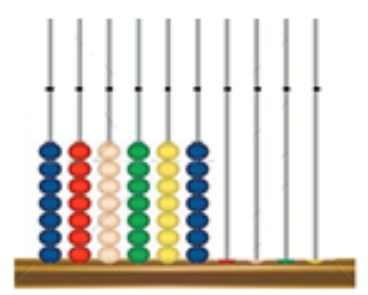

b)

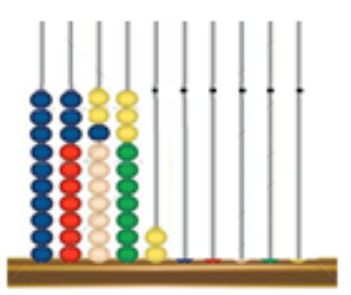

c)

Figura 42: a) $10 \times 10$, b) 6 bastões com 7 fichas, c) produto 42

Com essa estratégia os alunos podem observar a comutatividade da operação de multiplicação, ou seja, que 7 multiplicado por 6 é igual a 6 multiplicado por 7. Na figura 13a foram retiradas de cada bastão 4 fichas, ficando cada bastão com 6 fichas esféricas e de seguida foram retiradas todas as fichas de 3 bastões, ficando 7 bastões com 6 fichas cada. Reorganizando as fichas, obtemos novamente 4 bastões completos, com 10 fichas em cada um, e 2 fichas num outro bastão (figura 13b). 


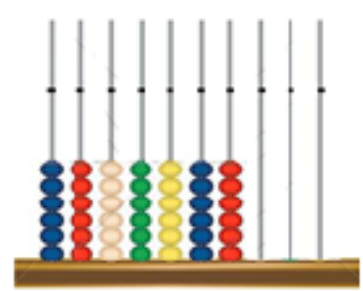

a)

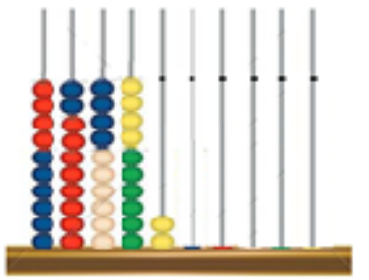

b)

Figura 53: a) 7 bastões com 6 fichas, b) produto 42

\section{CONSIDERAÇÕES FINAIS}

Os tópicos da História da Matemática e as estratégias e metodologias apresentadas neste trabalho são uma pequena amostra das inúmeras potencialidades da introdução desses assuntos nos processos de ensino e aprendizagem de determinados conteúdos da Matemática ao nível do Ensino Básico. Consoante o ano e o ciclo em que o aluno está inserido, podemos desenvolver e adaptar outras estratégias recorrendo também a outras áreas do saber, promovendo e enriquecendo, deste modo, a interdisciplinaridade.

Em cada um dos temas abordados houve a preocupação de apresentar uma estratégia, que pode ser transformada numa metodologia, que fosse capaz de satisfazer vários níveis de ensino e deixando à consideração outras eventuais aplicações mais complexas.

Motivados e induzidos pelos antigos textos matemáticos podemos planear atividades, estratégias e metodologias para dinamizar e enriquecer o processo de ensino-aprendizagem dos mais diversos temas e para os mais variados fins. A História da Matemática está repleta de problemas, muitos deles, ainda atuais, e o modo como foram solucionados são uma verdadeira fonte inspiradora para a transmissão e compreensão de conteúdos matemáticos.

\section{SOBRE OS AUTORES:}

\section{Helena de Fátima Sousa Melo}

Professora Auxiliar do Departamento de Matemática e Estatística da Faculdade de Ciências e Tecnologia da Universidade dos Açores, Centro de Estudos Humanísticos da Universidade dos Açores

(helena.fs.melo@uac.pt])

\section{Maria do Carmo Carvalho Sousa da Cunha Martins}

Professora Auxiliar do Departamento de Matemática e Estatística da Faculdade de Ciências e Tecnologia da Universidade dos Açores, Centro de Estudos Humanísticos da Universidade dos Açores

maria.cc.martins@uac.pt 